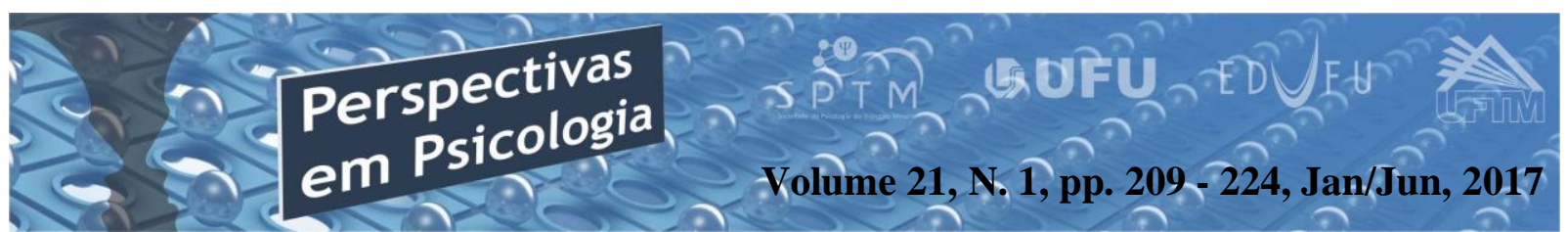

\title{
AS CONSEQUÊNCIAS DA HISTERECTOMIA NA SEXUALIDADE FEMININA
}

\author{
Hanielly Cristinny Mendes Carvalho \\ Moisés Fernandes Lemos \\ (Universidade Federal de Goiás, Regional Catalão - UFG/RC)
}

\begin{abstract}
Resumo
A histerectomia, um dos procedimentos cirúrgicos mais realizados no Brasil, é caracterizada como a remoção total ou parcial do útero e, gera diferentes sentimentos nas mulheres, que consideram esse órgão o representante de sua feminilidade e sexualidade. Este estudo qualitativo objetiva avaliar quais as repercussões que a histerectomia causa na sexualidade feminina. Para sua efetivação, foram realizadas entrevistas semiestruturadas com quatro mulheres histerectomizadas, escolhidas intencionalmente. Essas entrevistas, submetidas aos procedimentos da Análise Fenomenológica Interpretativa, levantaram as seguintes categorias de análise: reações frente ao diagnóstico; corpo e identidade; sexualidade. Os resultados obtidos permitiram concluir que o nível socioeconômico que as participantes estão inseridas interfere no modo como vivenciam a histerectomia. As mulheres deste estudo têm sua identidade pautada no ato de ser mãe e deixam sua sexualidade em segundo plano, confirmando a ideia de que vieram ao mundo para procriação e satisfação do parceiro, excluindo o seu próprio prazer.
\end{abstract}

Palavras-chave: histerectomia; útero; sexualidade.

\section{Abstract \\ The Consequences of Hysterectomy in Female Sexuality}

Hysterectomy, one of the most performed surgical procedures in Brazil, is characterized as total or partial removal of the uterus, and generates different feelings in women, who consider this organ the representative of their femininity and sexuality. This qualitative study aims to evaluate the repercussions that hysterectomy causes on female sexuality. For its effectiveness, semi-structured interviews were conducted with four hysterectomized women, chosen intentionally. These interviews, submitted to the Interpretive Phenomenological Analysis procedures, raised the following categories of analysis: reactions to the diagnosis; body and identity; sexuality. The obtained results allowed to conclude that the socioeconomic level that the participants are inserted interferes in the way in they experience the hysterectomy. The women of this study have their identity based on being a mother and leave their sexuality in the background, confirming the idea that they came to the world for procreation and satisfaction of the partner, excluding their own pleasure.

Key words: hysterectomy; uterus; sexuality. 


\section{I - Introdução}

A mulher vem ganhando cada vez mais espaço na sociedade. Espaço esse conquistado por meio de lutas: por direito ao voto, por igualdade entre os sexos, por direito ao próprio uso do seu corpo, dentre outras. Todavia, a mulher ainda é representada nos meios de comunicação pela ideia de que veio ao mundo para procriação e é a partir da reprodução que encontra sua feminilidade.

Essa visão do feminino, voltado para servir a finalidade reprodutiva excluindo o prazer, foi engendrada nos tempos primórdios, interferindo na forma como a mulher vivencia sua sexualidade. Eizirik (2001) fala sobre a fertilidade como atributo máximo da mulher, como prova de sua feminilidade. A fertilidade, portanto, seria vista como uma virtude e a esterilidade como uma punição ou fracasso. A partir disso, pode-se destacar que é, deste ponto, que se iniciam os conflitos da mulher, quando esta é submetida à histerectomia.

A histerectomia é um procedimento cirúrgico realizado em grande número para a remoção total ou parcial dos órgãos reprodutivos internos femininos, para tratamento na cura de miomas e cânceres de colo de útero, prolapsos uterinos, hemorragias, dor pélvica, endometriose, entre outras doenças. No Brasil, é a segunda cirurgia mais frequente entre as mulheres em idade fértil; estima-se que 20 a $30 \%$ das mulheres serão submetidas a esta operação até a sexta década de vida (Jamarino, 2009).

A histerectomia pode ter efeitos negativos em nível do bem-estar psicológico e somático, pois, além de suas funções biológicas, como a reprodução de hormônios, o útero (palavra originária do grego hystera), que é um órgão feminino, musculoso, oco e elástico, no qual se processa o desenvolvimento embrionário, é associado à feminilidade por relacionar-se ao papel reprodutor da mulher e à sua vida sexual. Isso significa que as mulheres podem ver o útero como aspecto importante da feminilidade, de maneira que a sua perda se refletirá na forma como elas percebem sua capacidade de fêmea, incluindo o desejo sexual. A autoestima fica baixa, pois o corpo sofre mudanças e a imagem corporal se abala, podendo haver ganho de peso, de tal modo que a identidade feminina se perde (Sbroggio, Osis \& Bedone, 2005). 


\section{AS CONSEQUÊNCIAS DA HISTERECTOMIA NA SEXUALIDADE FEMININA}

Segundo Machado (2005), a

identidade feminina está diretamente ligada ao útero. Freire e Mattos (1996) destacam que muitas mulheres consideram o período menstrual como um período desagradável, no entanto, entendem sua função como fundamental para proporcionar a probabilidade da procriação, aumento do desejo sexual e manutenção hormonal. Portanto, quando uma mulher é submetida à histerectomia é preciso que ela tenha conhecimento e esclarecimentos dos efeitos que podem ser causados ao seu corpo.

$$
\text { Cosmo e Carvalho }
$$
argumentam que a cirurgia para retirada do útero produz emoções conflitivas, traumáticas, de insegurança e ansiedade. Isso porque, além dos medos, que tradicionalmente uma cirurgia pode despertar nas pessoas, no caso da histerectomia acrescenta-se tais dúvidas e inquietudes com respeito à condição sexual da mulher após a retirada do útero. Essas inquietudes também são geradas pela falta de informação a respeito desse órgão feminino ou à crença em mitos.

Real, Cabeleira, Nascimento, Braz e Pivetta (2012) afirmam que a histerectomia pode determinar uma série de alterações, desde as condições físicas até perturbações emocionais. Acredita-se que mulheres submetidas a esta cirurgia podem apresentar alterações no autoconceito, sintomas depressivos e psicossomáticos, dificuldade de relacionamento sexual e conjugal, devido a associações psicológicas feitas entre a procriação e a sexualidade. No entanto, as reais consequências da realização da histerectomia sobre a qualidade da vida sexual posterior à cirurgia são controversas e dependem diretamente da intensidade dos sintomas pré-cirúrgicos, das condições emocionais da paciente e da qualidade do relacionamento estabelecido com o parceiro (Auge, Rossi \& Aoki, 2009).

Algumas mulheres, de acordo com Jamarino (2009), acreditam que sem o útero perderão o valor de ser mulher, pois sem a condição de gerar filhos passarão a ser vistas de outra maneira pela sociedade. Elas apresentam medo no pré e no pósoperatório, sentem-se como se estivessem faltando um pedaço de si. Elas temem a morte, a anestesia, o procedimento em si, a recuperação. Para tentar obter controle sobre esses medos, essas mulheres précirúrgicas lançam mão de algumas estratégias, como: depositar confiança na equipe de saúde; acreditar em Deus acima de qualquer coisa; controlar o pensamento e ter sempre a companhia de alguém conhecido.

Conforme Nunes, Gomes, Padilha, Gomes e Fonseca (2009), a maioria das 
mulheres considera a cirurgia como um evento negativo, ancorando as vivências pós-operatórias na impossibilidade de se tornarem mães e, principalmente, na incapacidade de manterem o casamento, nas incertezas quanto à capacidade de sentirem prazer e de serem socialmente aceitas.

É a partir de dados como estes,que Salvador, Vargens e Progianti (2008) ressaltaram a importância de lançar um olhar extensivo sobre a sexualidade, pois o ato sexual compreende apenas uma face dela. A sexualidade de uma mulher está na forma como ela se expressa em sua vida, em seu meio; dá o tom a sua maneira de conduzir a sua vida. Vale destacar que, segundo Ramos (2013), o feminino transcende o abordado pelo movimento feminista. Hoje, a mulher com suas conquistas não é menos enigmática em seu ser e em sua constituição e, é na experiência do amor e do sexo em relação a um gozo sem limite, do qual a psicanálise se encarrega de explicar, que pode se constituir a feminilidade.

Para Paula (2006), o tratamento é centrado na cura de um corpo físico que adoece, o cuidado prestado às mulheres tem como principal foco as questões biológicas, relegando a um segundo plano a subjetividade do ser-mulher. Como apontam Melo e Barros (2009), o útero aparece investido de valores vinculados à sexualidade e ao prazer feminino, sendo considerado um dos mais significativos órgãos da mulher e importante representante de sua feminilidade.

Diante desta declaração, nota-se a relevância de se estudar as condições emocionais por quais passam essas mulheres antes, durante e após a cirurgia, bem como a importância de oferecer a elas apoio psicológico. Partindo dessa breve explanação acerca da condição da mulher frente ao procedimento cirúrgico de retirada do útero, faz-se necessário investigar a seguinte questão: quais as repercussões da histerectomia na sexualidade feminina?

Realizar um estudo neste campo é indispensável, visto que a histerectomia é um dos procedimentos mais realizados atualmente no Brasil, que gera desconforto à mulher, a qual, muitas vezes, se perde em meio a tantos mitos e desconhece seu próprio corpo. Melo e Barros (2009) ressaltam o mistério e o tabu que cercam o corpo da mulher, tanto que, a anatomia dos órgãos sexuais e reprodutivos femininos é desconhecida por muitas mulheres. Nomear o corpo feminino é afirmar sua existência, sua complexidade e não conhecer o próprio corpo pode implicar em 


\section{AS CONSEQUÊNCIAS DA HISTERECTOMIA NA SEXUALIDADE FEMININA}

não reconhecer o seu funcionamento e a sua sexualidade. Embora a sexualidade não se restrinja apenas aos órgãos sexuais, ela perpassa por todo o corpo e está intimamente ligada à subjetividade, sendo que o conhecimento dos órgãos contribui para desmistificar e quebrar os tabus, que envolvem o corpo da mulher e sua relação com o sexo.

O interesse por essa questão surgiu ao acompanhar mulheres histerectomizadas no Hospital Municipal de Pires do Rio GO, no período de janeiro a março de 2015, quando foi notado que tais mulheres dão ao útero uma grande importância como garantia de ser mulher, sem nem compreender o verdadeiro significado deste órgão. Com essa percepção, as mulheres sofrem abalos em sua identidade feminina, porque, para elas, o útero simboliza a sua capacidade sexual. Com a retirada dele, a mulher passa a sentir-se diminuída, acreditando estar incapacitada sexualmente para sentir prazer.

Visto que o útero é considerado um importante órgão, representante da capacidade sexual e da feminilidade da mulher, concorda-se com Nunes et al. (2009), que é essencial disponibilizar um espaço de problematização e escuta acerca do viver sem útero, da feminilidade e da sexualidade, a fim de prevenir conflitos pessoais e conjugais entre as mulheres em processo de histerectomia. Sbroggio, Osis e Bedone (2005) ressaltam a necessidade de abordar a retirada do útero a partir de uma perspectiva de atenção integral à saúde das mulheres e no contexto de humanização do atendimento, em que os mitos sejam confrontados com a informação científica, de maneira que lhes seja permitido vivenciar a cirurgia e o pósoperatório do modo menos inquietante e mais satisfatório.

Sendo assim, o objetivo geral deste estudo é compreender qual a repercussão da histerectomia na sexualidade feminina. Para isso, faz-se necessário: a) conceituar histerectomia, expondo as possíveis conseqüências que ela pode gerar na sexualidade feminina; b) entrevistar mulheres histerectomizadas; c) analisar os dados coletados nas entrevistas e d) apresentar os resultados, dialogando com as informações científicas.

\section{II - Metodologia}

O presente estudo classifica-se como uma pesquisa qualitativa, fazendo uso das ferramentas oferecidas pela Análise Fenomenológica Interpretativa (AFI). A AFI trabalha com amostras pequenas e tem como principal interesse a análise do modo como os indivíduos dão 
sentido às suas experiências. Ela pretende fornecer uma exploração detalhada acerca dessas experiências pessoais, bem como um exame preciso do modo como os participantes as percebem.

Portanto, em um estudo de AFI, dáse importância ao significado particular que as experiências, os estados, os eventos e os objetos têm para os participantes. A AFI preocupa-se com questões que têm consequências significativas para o participante, tanto de um modo permanente quanto em um momento crítico de sua vida. Essas questões, frequentemente, dizem respeito a identidade e a uma percepção de si mesmo, pois as análises completas de relatos individuais de experiências ou de eventos importantes quase sempre tocam o ser e a identidade (Smith \& Eatough, 2010).

A pesquisa foi realizada na cidade de Pires do Rio-GO, situada na mesorregião do Sul Goiano, a qual foi fundada em 9 de novembro de 1922, à margem da ferrovia. Seu nome foi dado em homenagem ao Ministro de Viação e Obras Públicas do Governo Epitácio Pessoa, Dr. José Pires do Rio, que visitou o local do município em agosto de 1921 para inspecionar as obras. Sua área é de $1073,369 \mathrm{~km}^{2}$ e a população de 30.930 habitantes. O IDH-M do município é 0,785 e o PIB per capita é 12664,43 (IBGE, 2016). A escolha de Pires do Rio - GO foi intencional.

Como instrumento de pesquisa foi utilizado a entrevista semiestruturada, por se tratar de um recurso flexível para a coleta de dados, que permite uma interação entre o pesquisador e os participantes, oferecendo maior oportunidade para avaliar atitudes, condutas, reações, podendo o participante ser observado naquilo que diz e como diz (Marconi \& Lakatos, 2003). As entrevistas foram elaboradas e revisadas com cautela, baseadas em estudos anteriores com mulheres que passaram pelo mesmo procedimento cirúrgico, a fim de investigar a dúvida que deu origem ao presente estudo. Tais entrevistas visaram obter, de cada participante, informações sobre o histórico familiar e pessoal, número de filhos, motivo da indicação cirúrgica, importância do útero para elas, assim como modificações percebidas no corpo, sexualidade e feminilidade após a histerectomia.

A amostragem do estudo foi composta por quatro participantes do sexo feminino, que realizaram histerectomia, escolhidas, intencionalmente, mediante convite e adesão ao estudo. Não houve distinção prévia de faixa etária, 


\section{AS CONSEQUÊNCIAS DA HISTERECTOMIA NA SEXUALIDADE FEMININA}

escolaridade, raça ou condição econômica.

Para a efetivação do estudo foram realizados dois encontros com cada uma das participantes em suas próprias residências. No primeiro encontro foram fornecidas informações sobre a pesquisa e as condições de realização desta, esclarecendo sobre as diferentes etapas do estudo, para que, a partir do exposto, pudessem tomar a decisão de participar ou não. Mediante aceitação, foi assinado um Termo de Consentimento Livre e Esclarecido, conforme previsto na Resolução 466/2012, combinada a Resolução 510/2016, que estabelece as normas e regulamenta a realização de pesquisa com seres humanos, ambas editadas pelo Conselho Nacional de Saúde. $\mathrm{Na}$ oportunidade foi realizada a entrevista de coleta de dados propriamente dita. $\mathrm{O}$ segundo encontro visava a devolutiva, ou seja, o retorno à participante quanto aos resultados do estudo.

As entrevistas foram realizadas individualmente, garantindo o conforto das participantes e o sigilo das informações coletadas, conforme previsto na legislação vigente no país. Foram ainda audiogravadas e transcritas na íntegra, mediante autorização expressa. Os dados colhidos foram submetidos à análise de conteúdo, conforme previstonos procedimentos da AFI, sendo eles: a) leituras rigorosas e detalhadas dos dados a fim de se obter uma ampla perspectiva, de modo que futuras interpretações tenham como base o relato da participante; b) identificar os temas iniciais e organizar em feixes e examinar em relação aos dados; c) refinar os temas, condensá-los e examinálos, conforme as relações entre si e d)exposição narrativa da interpretação entre a atividade interpretativa do pesquisador e o relato que a participante fez de sua experiência (Smith \& Eatough, 2010).

As participantes deste estudo possuem entre 37 e 77 anos de idade, todas casadas, mãe de dois ou três filhos. Duas delas possuem ensino fundamental incompleto, uma com ensino médio completo e, outra, graduada. Com relação à ocupação, temos uma manicure, uma aposentada, uma cabeleireira e uma diarista. As indicações para realização da histerectomia foram hemorragia, miomas ou prolapsos uterinos. É importante ressaltar que todas possuem filhos e, apesar da diferença de idades, passaram pelo procedimento cirúrgico entre 30 - 40 anos de idade. Duas delas optaram pela rede particular e as outras duas pelo Sistema Único de Saúde (SUS). Todas retiraram apenas o útero, preservando os ovários e nenhuma fez reposição hormonal. 
As participantes da pesquisa, que foram chamadas de P1, P2, P3 e P4, tiveram suas respostas agrupadas em categorias apresentadas da seguinte forma:

\begin{tabular}{|c|c|c|}
\hline Categorias Gerais & Categorias Específicas & Subcategorias \\
\hline \multirow{3}{*}{$\begin{array}{c}\text { Reações ao diagnóstico de } \\
\text { histerectomia }\end{array}$} & Redes de atendimentos & $\begin{array}{c}\text { SUS X Rede particular X } \\
\text { Médicos }\end{array}$ \\
\cline { 2 - 3 } & Primeiros pensamentos & Medo de câncer e da morte \\
\hline \multirow{5}{*}{ Corpo e Identidade } & Função do útero & Gerar filhos \\
\cline { 2 - 3 } & Modificações pré cirúrgicas & Inchaço \\
\cline { 2 - 3 } & Modificações pós cirúrgicas & Ciclo menstrual irregular \\
\cline { 2 - 3 } & & Sentimento de vazio, oco \\
\cline { 2 - 3 } & & Ganho de peso/ Inchaço \\
\cline { 2 - 3 } & $\begin{array}{c}\text { Reações frente às } \\
\text { modificações }\end{array}$ & Libertação \\
\hline Sexualidade & Desempenho sexual & Oparceiro não reclamou \\
\hline & Relação com o parceiro & Apoio do parceiro \\
\hline
\end{tabular}

Figura 1: Demonstrativo das Categorias de Repostas Adotadas no Estudo.

\section{III - Resultados e Discussões}

A partir das respostas das quatro participantes, é possível pensar e articular os três tópicos levantados na entrevista: reações ao diagnóstico de histerectomia; corpo e identidade; sexualidade.

No que diz respeito às reações frente ao diagnóstico de histerectomia, podemos constatar que, o modo como cada participante reagiu diante da notícia teve fortes influências da equipe médica e do contexto sociocultural, ao qual cada participante está inserida: as mais velhas e com um pouco mais de estudo vivenciaram a histerectomia mais anuentes e tranquilas.
P1 passou por mais dificuldades ao tentar realizar o procedimento cirúrgico pelo SUS, relatando sua indignação em relação ao médico: "O ginecologista de lá (Hospital do SUS), que não vale a pena citar o nome, nunca me examinou, ele escreveu nos meus exames, na prevenção e no exame de sangue, que eu estava com câncer".

Com dúvida e medo desse diagnóstico decidiu procurar a rede particular, na qual encontrou tranquilidade para passar pelo procedimento: "Tudo no particular é diferente né". P3 e P4 realizaram o procedimento na rede pública de saúde e tiveram uma experiência diferente da P1, conforme expôs P3: “[...] 


\section{AS CONSEQUÊNCIAS DA HISTERECTOMIA NA SEXUALIDADE FEMININA}

teve um médico que me pôs tão apavorada, falou que eu já estava era com câncer [...]. Ele me arrebentou naquele dia. [...]. Depois de 4 meses eu consegui pelo SUS e foi tudo tranquilo".

Por meio desses relatos, podemos concluir que Jamarino (2009) estava certo ao afirmar que a confiança estabelecida entre essas mulheres e suas equipes médicas são essenciais para se manterem calmas no período pré-operatório. Como essa é uma cirurgia realizada com frequência no Brasil, os profissionais da saúde veem este procedimento como simples e de rotina, o qual traz apenas como consequências para as mulheres a perda da possibilidade de reprodução e a parada das menstruações. O que não representaria prejuízo à saúde, a partir de um ponto de vista biológico, confirmando o que Paula (2006) diz, que o tratamento é centrado na cura de um corpo físico que adoece, relegando a um segundo plano a subjetividade do ser-mulher.

O SUS vem sofrendo com a falta de investimentos, tanto em materiais e instrumentos quanto em profissionais de qualidade. Porém, se houver um atendimento pautado na humanização da saúde e não somente na eliminação do sintoma/doença, as chances de uma recuperação com qualidade de vida é maior. Apenas P1 recebeu orientação e escuta psicológica durante o período em que estava no hospital. É preciso pensar no bem estar psicológico do paciente e isso tem sido mudado com a entrada recente de psicólogos na rede hospitalar pública e privada.

Continuando a examinar as reações frente ao diagnóstico, as participantes apresentaram medo da morte ou do desenvolvimento de um câncer que, na verdade, relaciona-se ao mesmo temor, pois este é identificado como uma doença diretamente relacionada à morte (Ferreira $\&$ Lemos, 2016). Identificamos esse medo nos discursos de todas as participantes:

P1: "Porque eu esperava a morte, porque é duro".

P2: "um mioma com suspeita de C.A. (câncer)".

P3: "minha família tem muito problema de câncer e eu tenho medo". P4: "Medo. Tanta coisa esquisita e o médico falava assim 'Se a senhora não tirar dá problema mais sério, a senhora pode provocar um câncer'”.

O segundo tópico levantado para a análise das entrevistas foi como as participantes perceberam o seu corpo antes e depois da cirurgia e de que forma isso afetava sua identidade. As quatro participantes atestaram que a função do útero é gerar filhos e, como todas elas já os 


\section{HANIELLY CRISTINNY MENDES CARVALHO, MOISÉS FERNANDES LEMOS}

possuem, o procedimento não foi visto como um problema a partir deste aspecto. Deste modo, a representação do útero para essas mulheres está relacionada apenas como um órgão para a procriação e, por não ter mais o desejo de engravidar, a sua retirada foi considerada "natural". Neste ponto, Eizirik (2001) está certo ao afirmar que a fertilidade é vista como atributo máximo da mulher, como prova de sua feminilidade. As mulheres deste estudo se enxergam como um ser para procriação, já que suas identidades estão pautadas na condição de "ser mãe", conforme observamos nos seguintes discursos:

P2: “A função dele é gerar filhos. Gerou, depois disso ele se transforma em um saco de infecção".

P3: "O útero serve mesmo é só para você ter filhos e depois isso acabou, isso é bobagem. [...]. Teve filho, precisou, tira!".

A prova de que a identidade dessas participantes está pautada na maternidade fica mais manifesta ao relatarem as mudanças sofridas por seus corpos no período pré e pós-operatório, trazendo a gravidez como uma possibilidade:

P1: "[...] tinha vez que eu saia na rua e o povo perguntava se eu estava grávida de sete meses do tanto que a minha barriga inchava".

P3: “[...] minha barriga cresceu muito, eu achei até que estava grávida".

No período pré-operatório as participantes sofreram com as irregularidades do ciclo menstrual. P1, P3 e P4 falaram sobre as dificuldades para manter uma vida social e sexual devido a essas irregularidades:

P1: “[...] era muita hemorragia e eu ficava muito fraca, sem poder sair de casa".

P3: “[...] eu tinha muita menstruação, demais da conta. Eu estava limpando a casa e descia aquelas bolas de sangue. Não podia sair, não podia namorar".

P4: “[...] eu menstruava assim diretão, estava tendo hemorragia diretão".

Freire e Mattos (1996) destacam que muitas mulheres consideram o período menstrual como uma fase desagradável, entretanto entendem sua função como fundamental para proporcionar a probabilidade da procriação. Após a cirurgia, as participantes da pesquisa, que já são mães, consideraram a inexistência do ciclo menstrual um alívio:

P2: "[...] aquele sangramento todo mês é muito triste". 


\section{AS CONSEQUÊNCIAS DA HISTERECTOMIA NA SEXUALIDADE FEMININA}

P3: "Nossa, foi bom demais, é muito bom, você não tem menstruação, você não tem sofrimento".

P4: “A única coisa é que a gente não menstrua, é a diferença. Mas eu, pra mim, sou a mesma mulher. Eu não sinto falta do sangramento de jeito nenhum, nunca!".

Segundo Sbroggio, Osis e Bedone (2005) é comum mulheres histerectomizadas relatarem um sentimento de vazio e oco no lugar do útero após a cirurgia. Das quatro participantes, somente P1 mencionou esse vazio: "Mas até hoje dói, e eu falo assim oh, o lugar do útero fica vago". As outras participantes não se referiram a esse vazio, conforme P2 afirmou: "Não existe vazio, não existe oco após a histerectomia. É tudo coisa da cabeça da mulher". Cabe ressaltar que, a participante que afirmou se sentir oca é a mesma que teve problemas com o SUS, é a mais nova do grupo pesquisado, a que tem menor tempo de cirurgia e pouco estudo e,a única que não declarou estar ou não satisfeita em se livrar do ciclo menstrual. Esse dado confirma que o modo como as mulheres recebem a notícia e o tratamento está diretamente ligado a sua satisfação com o procedimento realizado e ao meio social em que estão inseridas.

Outra modificação, muito citada nas literaturas revisadas para a efetivação deste estudo, é o ganho de peso após a histerectomia, o qual se fez presente na fala de P4: "Engordei muito". Mesmo sofrendo inúmeras modificação no corpo, essas mulheres relataram melhorias para a saúde após o procedimento cirúrgico, pois viram a cirurgia como condição para se livrar de um incômodo. Como podemos observar a seguir:

P1: “[...] é melhor você fazer a cirurgia para ficar bem do que você estar com todos os órgãos e não estar se sentindo bem".

P3: “Aquilo era horrível. Eu não tinha segurança para sair. A cirurgia para mim foi uma libertação, uma libertação".

P4: “[...] depois que tirei o útero tudo melhorou".

O estudo com essas mulheres permite-nos ressaltar que Cosmo e Carvalho (2000) acertaram ao dizer que a histerectomia pode trazer a sensação de alívio ocasionada pela possibilidade de retomada das condições sociais e sexuais,outrora interrompidas pelos sintomas que as acometiam. Muitos estudos já relataram que algumas mulheres histerectomizadas referem à sensação de alívio após a remoção do útero, ocasionada pelo fato de não mais sentirem dores abdominais e sangramentos, advindos das 
patologias uterinas. A cessação destes sintomas cria nestas mulheres a expectativa de retomo ao bem-estar social e conjugal, antes comprometido.

Ao expor sobre o quão bem lhe fez a histerectomia, P2 entrou no terceiro tópico da análise: a sexualidade. Após a cirurgia, P2 se sentiu motivada para iniciar uma nova vida sexual sem os sinais e sintomas desagradáveis do ciclo menstrual, como observa-se em seu depoimento: “[ [...] ficou melhor ainda, porque quando o marido queria talvez não poderia por causa da menstruação, depois, qualquer dia era dia". Entretanto, falar sobre sexualidade, principalmente a da mulher, ainda é tabu para a sociedade brasileira e, principalmente, para as próprias mulheres. Quando indagadas, se receberam apoio do parceiro durante o procedimento, disseram:

P1: "Não, meu marido se manteve da mesma forma. Até muito preocupado". P2: "Ele não mudou, permaneceu do mesmo jeito que sempre foi”.

P3: "É, meu marido é uma pessoa muito boa. [...]. Tem marido que não, que arrebenta com a mulher, não querem saber".

P4: "Uai, meu velho nunca foi de demonstrar afeto, mas me senti segura".
Ao serem questionadas sobre alguma mudança na relação sexual, P1 foi direta na resposta: "mesma coisa”. P2, P3 e P4 também asseguraram que a relação sexual permaneceu a mesma, todavia adicionaram informações a respeito do parceiro:

P2: "Não teve alteração nenhuma, foi a mesma coisa. Se teve o marido nunca reclamou e eu nunca senti falta, foi sempre correspondido".

P3: “[...] quando eu fui ter a relação doeu porque eu fiz o períneo [...] meu marido obedecia e tudo".

P4: “Ah, eu não senti nada, porque meu velho já tá velho também né! (risos). Já não importa com isso nada".

Analisando estas respostas, é possível observar o jeito como essas mulheres se colocam como objeto de prazer para o outro, no caso, para seus maridos. O prazer delas fica em segundo plano, alimentando a visão de que a mulher veio ao mundo para servir a finalidade reprodutiva, excluindo-lhe o prazer e interferindo na forma como elas vivenciam sua sexualidade.

Melo e Barros (2009) não só
afirmam ser o útero um importante
representante da sexualidade e
feminilidade, bem como ressaltam o




\section{AS CONSEQUÊNCIAS DA HISTERECTOMIA NA SEXUALIDADE FEMININA}

mistério e o tabu que cercam o corpo da mulher, assinalando ao não conhecerem seu próprio corpo,isso pode implicar em não reconhecer o seu funcionamento e a sua sexualidade. Tudo isso está atrelado à construção de gênero em nossa sociedade, que além de controlar o corpo da mulher, reforça a submissão feminina com uma postura recatada, cautelosa e tímida, em contraste à representação da masculinidade, caracterizada pela força, virilidade, ousadia e a liberdade.

As dúvidas sobre a condição sexual da mulher após a retirada do útero são geradas pela falta de informação a respeito desse órgão feminino ou à crença em mitos. De acordo com Auge, Rossi e Aoki (2009), as reais consequências da realização da histerectomia sobre a qualidade da vida sexual posterior à cirurgia são controversas e dependem diretamente da intensidade dos sintomas pré-cirúrgicos, das condições emocionais da paciente e da qualidade do relacionamento estabelecido com $\mathrm{O}$ parceiro. Ficou evidente que as mulheres deste estudo não mantêm um diálogo com seus parceiros à respeito da sexualidade e isso refletiu na forma como relataram o apoio do parceiro e a relação sexual após o procedimento: "mesma coisa!".

\section{Considerações Finais}

A partir deste estudo foi possível explanar as questões que a histerectomia pode causar na vida da mulher. A maioria das pesquisas sobre esta temática aponta que a retirada do útero pode ser causadora de repercussões afetivas e psicológicas devido à associação deste órgão com o conceito de feminilidade e sexualidade, uma vez que a identidade feminina está pautada na maternidade.

Após analisar as respostas obtidas nas entrevistas, foi constatado que o fator cultural e social é um forte aliado, quanto às percepções das mulheres acerca das possíveis mudanças corporais, sexuais e conjugais ocorridas após a histerectomia. Mulheres com pouco estudo e de classes sociais mais baixas tendem a ficar mais apavoradas, como foi o caso de P1. Além de fatores socioculturais, a relação que essas mulheres mantêm com seus parceiros e o fato de já terem filhos também influenciaram suas respostas.

Foi possível concluir que as mulheres deste estudo pautam sua identidade feminina no ato de ser mãe, quando ressaltam que o útero tem a finalidade somente de gerar filhos: "se já tiver filhos, pode fazer a histerectomia". Consoante os autores estudados abordados, a feminilidade está intimamente associada 


\section{HANIELLY CRISTINNY MENDES CARVALHO, MOISÉS FERNANDES LEMOS}

à capacidade de conceber, mas não se pode generalizar essa ideia. Para isso, é importante a realização de estudos similares com mulheres histerectomizadas que não possuem filhos.

Com relação à sexualidade, existe muito tabu ao falar sobre a sexualidade feminina, porque os conceitos machistas ainda fazem parte da sociedade, colocando a mulher como um ser que veio ao mundo para procriação e para a satisfação do homem, excluindo o prazer delas. Para as participantes deste estudo, a histerectomia não interferiu nas relações sexuais; porém, relatam sob a perspectiva do marido, que não percebeu nenhuma alteração, deixando de mencionar se realmente estavam satisfeitas com a própria sexualidade. O procedimento cirúrgico também não trouxe problemas para suas identidades, levando em consideração que todas já foram mães, estavam "preparadas" para ficar sem o útero.

Ainda que não tenha sido constatadas muitas repercussões na vida dessas mulheres que foram entrevistadas, é essencial disponibilizar um espaço de problematização e escuta acerca do viver sem útero, da feminilidade $\mathrm{e}$ da sexualidade. Não somente pensando em prevenir conflitos pessoais e conjugais entre as mulheres em processo de histerectomia, mas para discutir sobre essa identidade e sexualidade feminina, que coloca-se em segundo plano frenteao desejo do outro.

Como trazido e observado nos relatos das participantes, um fator gerador de estresse e que pode influenciar nas repercussões que a histerectomia pode causar na vida da mulher é, sem dúvidas, o tratamento que recebem da equipe hospitalar. É fundamental ressaltar a necessidade de abordar a retirada do útero a partir de uma perspectiva de atenção integral à saúde das mulheres e no contexto de humanização do atendimento, o em que os mitos sejam confrontados com a informação científica. No entanto, são necessários mais estudos sobre as questões físicas e emocionais, que este e outros procedimentos ginecológicos, podem trazer para a mulher. Mesmo porque, no campo da Psicologia, são poucos os estudos sobre esta temática.

O profissional de Psicologia, inserido nesse contexto, pode atuar acolhendo e dando suporte à paciente e seus familiares, esclarecendo dúvidas do pré e pós operatório, contribuindo para que o procedimento seja efetuado com maiores chances de sucesso. 


\section{Referências}

Auge, A. P. F., Rossi, L. M. \& Aoki, T (2009). Avaliação da sexualidade em mulheres submetidas à histerectomia para tratamento do leiomioma uterino. Revista Brasileira de Ginecologia e Obstetrícia, 31(10), 503-507.

Cosmo M. \& Carvalho J. W. A. Pensando sobre o período pré-operatório na histerectomia. Revista da Sociedade Brasileira de Psicologia Hospitalar, 3(1), 27-30.

Eizirik, C.L. (2001). O ciclo da vida humana: uma perspectiva psicodinâmica. Porto Alegre: Artmed Editora.

Ferreira, R. M. B. \& Lemos, M. F. (2016). A mulher e o câncer de mama: um olhar sobre o corpo adoecido. Perspectivas em Psicologia, 20(1), 178-201.

Freire, A. C; \& Mattos, J. S (1996). Humanização em saúde - estudos das percepções da mulher submetida a histerectomia. Disponível em:<http://www.psicometria.pc.br $>$. Acesso em: 04/06/2016

IBGE - Instituto Brasileiro de Geografia E Estatística. Censo Demográfico de 2016. Disponível em: <http://www.cidades.ibge.gov.br/v3/cidades/municipio/5217401>. Acesso em: 13/06/2016.

Jamarino, A. M. (2009). Análise da percepção corporal e sexual de mulheres histerectomizadas. 52f. Trabalho de Conclusão de Curso. Enfermagem. Centro Regional Universitário de Espírito Santo do Pinhal, SP.

Machado, N. P. (2005). Interfaces do Câncer. Revista Brasileira de Cancerologia. São Paulo, 5 (28). Disponível em: 〈http//:www.praticahospitalar.com.br>. Acesso em: 04/06/2016

Marconi, M. A. \& Lakatos, E. M. Fundamentos de Metodologia Científica. São Paulo: Editora Atlas.

Melo, M. C. B. D. \& Barros, É. N. D. (2009).Histerectomia e simbolismo do útero: possíveis repercussões na sexualidade feminina. Revista da SBPH, 12(2), 80-99.

Nunes, M. P. R. S., Gomes, V. L. O., Padilha, M. I., Gomes, G. C. \& Fonseca, A.D. (2009). Representações de mulheres sobre a histerectomia. Escola Anna Nery, Revista de Enfermagem, 13(3), 574-581. https://doi.org/10.1590/S1414-81452009000300017.

Paula A F (2006). Câncer cérvico-uterino: uma ameaça (in)evitável? Rev Enferm UERJ, 14(1), 123-29.

Pires do Rio - Go (cidade). Disponível em: <http://www.piresdorio.go.gov.br/>. Acesso em: 13/06/2016. 
Ramos, M. F. F. (2013). Os impasses da sexualidade feminina na obra de Freud. $79 f$. Dissertação (Mestrado em Psicologia) - Departamento de Psicologia, do Setor de Ciências Humanas Letras e Artes, Universidade Federal do Paraná, Curitiba.

Real, A. A., Cabeleira, M. E. P., Nascimento, J. R., Braz, M. M. \& Pivetta, H. M. F. (2012). Os efeitos da histerectomia sobre a sexualidade feminina. Saúde (Santa Maria), 38 (2), 123-130. https://doi.org/10.5902/223658346581.

Salvador, R. T., Vargens, O. M. C. \& Progianti, J. M. Sexualidade e histerectomia: mitos e realidade. Revista Gaúcha de Enfermagem. 29(2), 320-323.

Sbroggio, A. M. R., Osis, M. J. M. D. \& Bedone, A. J. (2005). O significado da retirada do útero para as mulheres: um estudo qualitativo. Revista de Associação Médica Brasileira, 51(5), 270-274. https://doi.org/10.1590/S0104-42302005000500018.

Smith, A. J. \& Eatough, V. (2010). Análise Fenomenológica Interpretativa. In: Breakwell, M. G. Schaw, C. F. Hammond, S. \& Smith, J. A. Métodos de pesquisa em psicologia. (pp 324-338), Porto Alegre: Artmed.

Os autores:

Hanielly Cristinny Mendes Carvalho é graduada em Psicologia, pela Universidade Federal de Goiás, Regional Catalão. E.mail: haniellycarvalho@outlook.com

Moises Fernandes Lemos é psicólogo clínico, especialista em Psicologia Clínica e em Filosofia, mestre em Psicologia e doutor em Educação. Atualmente, é professor adjunto na Universidade Federal de Goiás, Regional Catalão - UFG/RC. Endereço - Av. Anhanguera, 1201, Unidade 141, CEP 75702-610 - Catalão GO. E.mail - moisesflemos@yahoo.com.br

Recebido em: 20/04/2017.

Aprovado em: 23/06/2017. 